$9-1-2021$

\title{
Spontaneous closure of full thickness macular hole in the presence of an epiretinal membrane in a vitrectomised eye: $A$ case report
}

Rehman Siddiqui

Muhammad Umar Fawad

Nida Ahsan

Follow this and additional works at: https://ecommons.aku.edu/pakistan_fhs_mc_surg_ophthalmol

Part of the Eye Diseases Commons, Ophthalmology Commons, and the Surgery Commons 
CASE REPORT

\section{Spontaneous closure of full thickness macular hole in the presence of an epiretinal membrane in a vitrectomised eye: $A$ case report}

Rehman Siddiqui, ${ }^{1}$ Muhammad Umar Fawad, ${ }^{2}$ Nida Ahsan ${ }^{3}$

\begin{abstract}
We report the case of a spontaneous closure of full thickness macular hole (FTMH) in the presence of an epiretinal membrane (ERM) in a previously vitrectomised eye. The patient had undergone vitrectomy for rhegmatogenous retinal detachment and developed an ERM two weeks after the surgery, which converted into a FTMH after one week. Eight months after the vitrectomy, spontaneous closure of FTMH was observed with an improvement in best-corrected visual acuity (BCVA) from $20 / 200$ to $20 / 40$. The patient was followed up for four years, and the FTMH remained closed. Spontaneous closure of FTMH is possible even in the presence of an ERM. Follow-up examination with optical coherence tomography (OCT) may be considered before surgery for FTMH, particularly if the surgery is scheduled a few weeks later.
\end{abstract}

Keywords: Retinal Perforations, Epiretinal Membrane, Vitrectomy, Retinal Holes.

\section{DOI: https://doi.org/10.47391/JPMA.04-642}

\section{Introduction}

Full thickness macular hole (FTMH) is characterised by a complete thickness anatomic defect at the fovea, leading to decreased visual acuity, metamorphopsia, and central scotoma. ${ }^{1}$ Idiopathic macular holes usually occur in elderly patients and are more frequent in women.

Macular holes may be idiopathic or caused by a number of conditions including traumatic concussion injury, scleral buckle or vitrectomy surgery. ${ }^{2}$ The mechanism of secondary FTMH after vitrectomy for RRD is not well

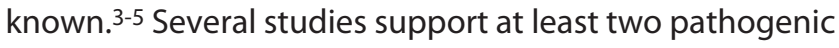
mechanisms for FTMH formation in the vitrectomised eyes.6,7 FTMH are retinal breaks in the fovea involving the partial to complete dehiscence of the neural retinal layers. Formation of an idiopathic or primary FTMH has been

1Department of Ophthalmology, Aga Khan University Hospital, Shahzad Eye Hospital, South City Hospital, Karachi, Pakistan, 2Department of Ophthalmology, Countess of Chester Hospital, Chester, UK, ${ }^{3}$ Department of Ophthalmology, Aga Khan University Hospital, Karachi, Pakistan.

Correspondence: Rehman Siddiqui. Email: rehman.siddiqui@gmail.com attributed to mechanical forces exerting tangential traction at the vitreomacular interface. ${ }^{8}$ Pars plana vitrectomy (PPV), gas-fluid exchange, and face-down positioning with or without ILM peeling is the first treatment option for medium and large FTMH. ${ }^{9}$ Spontaneous resolution of FTMH is known to occur, particularly in grade 1 macular hole. It is very rare for other grades of FTMH to close spontaneuouly. 10,11 FTMH which developed after vitrectomy can also close spontaneously. ${ }^{11}$

We report a case of post vitrectomy FTMH, as evidenced by Spectral Domain Optical Coherence Tomography (SDOCT), that closed spontaneously in spite of an associated ERM. Such a case has been reported for the first time in Pakistan. These changes were documented with serial spectral domain optical coherence tomography scans.

\section{Case Report}

A 51-year-old female presented to Shahzad Eye Hospital Karachi, in February 2014, with decreased visual acuity in her right eye since the past two days without any other associated symptoms. Her ocular history suggested bilateral uneventful cataract surgeries one year ago. On examination, the best corrected visual acuity was counting fingers at one metre in the right eye and 20/20 in the left eye. The IOP was $12 \mathrm{~mm} \mathrm{Hg}$ in both eyes. Fundoscopy revealed right eye macula off Rhegmatogenous Retinal Detachment (RRD). The left eye fundus exam was unremarkable. The patient underwent 25 -gauge pars plana vitrectomy on the same day, with cryopexy and 25\% SF6 tamponade.

The post-operative recovery was uneventful. Fifteen days later, there was a small bubble of SF6 gas in the eye, and the central area could be examined. Her vision improved from counting fingers to $20 / 200$. Slit-lamp biomicroscopy revealed attached retina with an ERM and a FTMH. These findings were confirmed on OCT (Figure).

The patient declined immediate further surgical intervention. She was followed- up thereafter. Spectral domain OCTs were performed at each visit which showed shrinkage of the macular hole from the first month onwards, and complete resolution of FTMH at the last visit two-and-a-half years after initial presentation. Her vision 


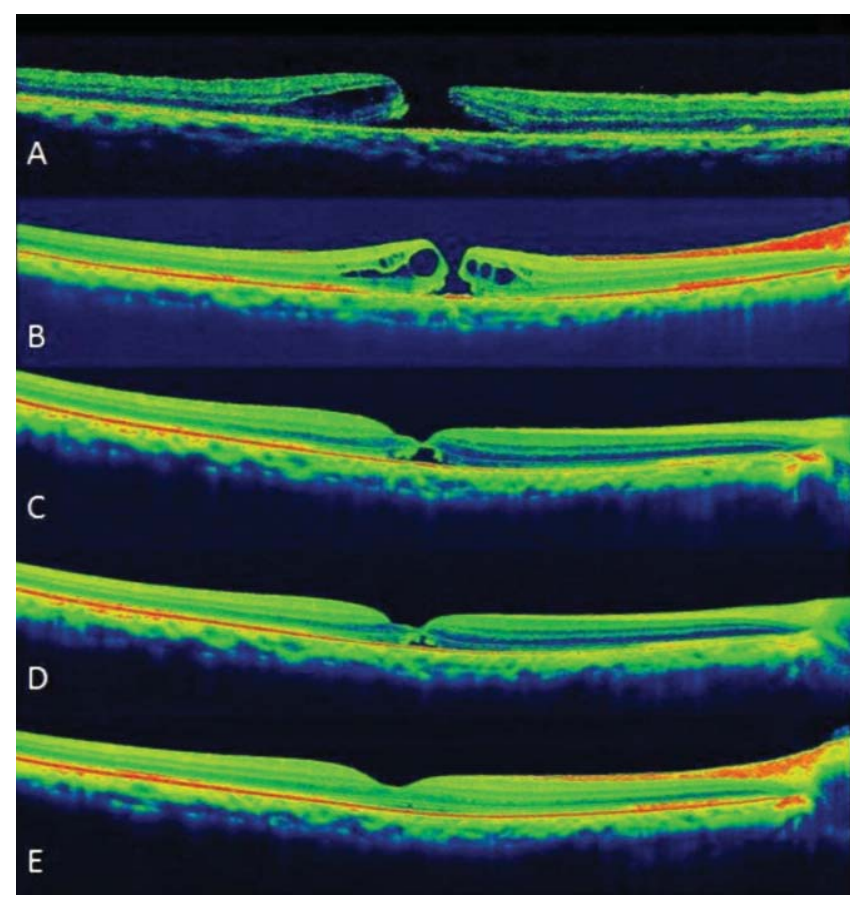

Figure: Spectral Domain OCT images of the right eye.

The top image clearly shows full thickness macular hole, with elevated edges and minimal intra-retinal cysts at the border of FTMH (Figure-[A])

At the first follow-up visit, there are intra-retinal cysts in the borders of the macula hole, but the FTMH looks smaller (Figure-[B])

Over the next eight months, the hole became smaller and closed completely (Figure-[C-E])

improved from $20 / 200$ to $20 / 40$. There was no metamorphopsia. She was followed annually for six years. The FTMH remains closed, and the ERM and visual acuity remain stable.

Consent was taken from the patient for the publication of the report.

\section{Discussion}

The degeneration of the inner retinal layers at the fovea, together with tangential vitreo-macular traction forces initiated during anomalous posterior vitreous detachment are thought to be the causative factor in the formation of FTMH. ${ }^{4}$ Therefore, vitrectomy with ILM peeling followed by gas tamponade is the current standard of care for FTMH. It is important to perform a $360^{\circ}$ wide ILM peel around the hole to remove all possible traction. ${ }^{5}$

The natural history of FTMH is poor because visual acuity worsens with time and the hole tends to enlarge. However, there are reports of spontaneous closure of $\mathrm{FTMH}$. This has been described in the literature in both vitrectomised as well as non-vitrectomised eyes. ${ }^{12,13}$
In our case, SD-OCT revealed an epiretinal membrane, found adherent to the retinal surface. Since the eye had been vitectomised, therefore, no antero-posterior traction was present. Smiddy reported a similar case with pre-existing ERM, and hypothesised that ERM contraction could be a factor to narrow the gap and allowing the glial tissue to bridge the FTMH. ${ }^{14}$

Michalewska suggested that irregular FTMH edges on OCT scans have a higher chance for spontaneous closure as compared to FTMH with smooth edges. ${ }^{14}$ Since our patient had an irregular FTMH surface due to ERM, this irregularity might have induced the migration of Muller cells and initiated a bridging effect leading to spontaneous closure of FTMH.

The exact mechanism of spontaneous macular hole closure is still unclear, but four different hypotheses have been proposed: complete vitreous detachment over the fovea releasing the antero-posterior tractional forces, formation of an epiretinal membrane resulting in hole shrinkage and closure, glial cell proliferation at the base of the hole, and growth of retinal tissue bridging over the hole. ${ }^{15}$

\section{Conclusion}

Spontaneous FTMH closure may take place in vitrectomised eyes in the presence of ERM. Although the mechanism of spontaneous closure of FTMH is not completely understood, we believe that in the absence of vitreous, the natural course of FTMH is different. Followup examination with repeat OCT is advised, when there is a delay between initial clinical assessment and surgery.

Disclaimer: The case was initially seen in 2014, however total resolution of FTMH took 2.5 years. Sometimes these macular holes open up again. We wanted to ensure we have sufficiently long follow up to support our claim of spontaneous resolution of FTMH.

Conflict of Interest: None to declare.

Funding Sources: None to declare.

\section{References}

1. Krasnicki P, Dmuchowska DA, Pawluczuk B, Proniewska-Skretek E, Mariak Z. Metamorphopsia before and after full-thickness macular hole surgery. Adv Med Sci. 2015; 60:162-6.

2. Forsaa VA, Lindtjørn B, Kvaløy JT, Frøystein T, Krohn J. Epidemiology and Morphology of Full Thickness Macular Holes. Acta Ophthalmol.2018; 96:397-404.

3. Hess JA, Michels S, Becker MD. Functional and Anatomic Outcomes of Primary and Secondary Internal Limiting Membrane Transplantation in Large and Persistent Macular Holes. Klin Monbl Augenheilkd. 2018; 235:1159-64.

4. Smiddy W, Flynn H. Pathogenesis of macular holes and therapeutic implications. Am J Ophthalmol.2004; 137:525-37. 
5. Cornish KS, Lois N, Scott N, Burr J, Cook J, Boachie C, et al. Vitrectomy with internal limiting membrane (ILM) peeling versus vitrectomy with no peeling for idiopathic full-thickness macular hole (FTMH). Cochrane Database Syst Rev. 2013; 6:CD009306.

6. Lee SH, Park KH, Kim JH, Heo JW, Yu HG, Yu YS, et al. Secondary macular hole formation after vitrectomy. Retina. 2010; 30:1072-7.

7. Garcia-Arumi J, Boixadera A, Martinez-Castillo V, Zapata MA, Fonollosa A, Corcostegui B. Macular holes after rhegmatogenous retinal detachment repair: Surgical management and functional outcome. Retina. 2011; 31:1777-82.

8. Duker JS, Kaiser PK, Binder S, Smet MD , Gaudric A, Reichel E ,et al. The International Vitreomacular Traction Study Group classification of vitreomacular adhesion, traction, and macular hole. Ophthalmology. 2013; 120:2611-9.

9. Ruoan Han, Chenxi Zhang, Xinyu Zhao, Youxin Chen. Treatment of primary full-thickness macular hole by intravitreal injection of expansile gas. Eye (Lond). 2019; 33:136-43.

10. Falkner-Radler $\mathrm{Cl}$, Gabriel M, Binder S. Spontaneous closure of an idiopathic macular hole 9 months after unsuccessful vitreoretinal surgery. Retin Cases Brief Rep. 2014; 8:157-60.

11. Tarib I, Zaoui K, Reda K, Oubaaz A. Spontaneous Closure of a Macular Hole in a Vitrectomized Eye for a Rhegmatogeneous Retinal Detachment: A Case Report. J Clin Exp Ophthalmol 2018;9:6

12. Shukla D, Rajendran A, Kim R. Macular hole formation and spontaneous closure after vitrectomy for central retinal vein occlusion. Graefes Arch Clin Exp Ophthalmol. 2006; 244:1350-2.

13. Smiddy WE. Spontaneous macular hole closure with appearance of epiretinal membrane: implications for therapy. Ophthalmic Surg Lasers Imaging. 2008; 39:237-8.

14. Michalewska Z, Cisiecki S, Sikorski B, Michalewski J, Kaluzny JJ, Wojtkowski M, et al. Spontaneous closure of stage III and IV idiopathic full-thickness macular holes-a two-case report. Graefes Arch Clin Exp Ophthalmol. 2008; 246:99-104.

15. Ozgonul C, Besirli CG. Macular hole closure following spontaneous release of vitreomacular traction. BMJ Case Rep. 2017; 2017: bcr2016218547. 